\title{
Synergetic Effect of La and Ba Promoters on Nanostructured Iron Catalyst in Fischer-Tropsch Synthesis
}

\author{
Yahya ZAMANI ${ }^{1,2}$, Mehdi BAKAVOLI ${ }^{1,{ }^{*}}$, Mohamad RAHIMIZADEH ${ }^{1}$, Ali MOHAJERI ${ }^{2}$, \\ Seyed Mohamad SEYEDI ${ }^{1}$ \\ ${ }^{1}$ Department of Chemistry, Ferdowsi University of Mashhad, Azadi Square, Mashhad, 91735-48974, Iran \\ ${ }^{2}$ Research Institute of Petroleum Industry (RIPI), National Iranian Oil Company; West Blvd., Near Azadi Sports Complex P.O.BOX \\ 14665-137, Tehran, Iran
}

\begin{abstract}
Effect of promoters such as Barium and Lanthanum has been investigated on the conventional nanostructured iron catalyst in Fischer-Tropsch synthesis (FTS). The nanosized iron-based catalysts were prepared by a microemulsion method with the general formulation of $100 \mathrm{Fe} / 4 \mathrm{Cu}, 100 \mathrm{Fe} / 4 \mathrm{Cu} / 2 \mathrm{La}, 100 \mathrm{Fe} / 4 \mathrm{Cu} / 1 \mathrm{La} / 1 \mathrm{Ba}$, and $100 \mathrm{Fe} / 4 \mathrm{Cu} / 2 \mathrm{Ba}$. The phase, structure, and morphology of the catalysts were characterized by X-ray diffraction, $\mathrm{N}_{2}$ adsorption, transmission electron microscopy, temperature-programmed desorption of $\mathrm{CO}_{2}$, and temperature-programmed reduction. The results indicated that the addition of promoters could improve the activity of Fe catalysts for FTS and WGS (water-gas shift reaction) and lower the gas fraction at the outlet. In addition, both Ba- and La-promoted Fe catalysts exhibit the highest activity due to the synergetic effect.
\end{abstract}

Key words: nanosized iron catalyst; microemulsion method; Fischer-Tropsch synthesis; promoter effect

CLC number: O643 Document code: A

Received 5 January 2012. Accepted 22 March 2012.

*Corresponding author. Tel: +98-511-8797022; Fax: +98-511-8795457; E-mail: mbakavoli@yahoo.com

This work was supported by the Research and Development of National Iranian Oil Company (NIOC).

English edition available online at Elsevier ScienceDirect (http://www.sciencedirect.com/science/journal/18722067).

Fischer-Tropsch synthesis (FTS, CO $+(1+n / 2) \mathrm{H}_{2} \leftrightarrow$ $\mathrm{CH}_{n}+\mathrm{H}_{2} \mathrm{O}$ ) has been recognized as a heterogeneous surface catalyzed polymerization process. During the reaction, hydrogenation of $\mathrm{CO}$ over the transition metal surface occurs to form $\mathrm{CH}_{x}$ monomers and then produce variety of hydrocarbons with a wide range of chain lengths and functional groups. FTS is an important process to produce hydrocarbon fuels from coal or syngas. Although several metals are active for FTS, only iron and cobalt catalysts are economically feasible in industrial application. Except low cost and availability, the high water-gas shift (WGS, $\mathrm{CO}+\mathrm{H}_{2} \mathrm{O} \leftrightarrow$ $\mathrm{CO}_{2}+\mathrm{H}_{2}$ ) activity makes Fe-based catalysts more suitable for the conversion of low $\mathrm{H}_{2} / \mathrm{CO}$ ratio syngas. Because the reserves of coal and natural gas are in abundance compared to crude oil, FTS can supply ample liquid fuels for the world for extended period of time compared to petroleum refining [1-14].

Potassium has been widely used as a promoter for Fe-based catalysts. It increases the alkene yield and lowers the fraction of $\mathrm{CH}_{4}[15,16]$. Potassium can also improve the activity of Fe-based catalysts in FTS and WGS reactions [17-22]. Copper is normally added to the catalysts as a chemical promoter to facilitate reduction of hematite [23]. Mn-promoted Fe catalysts have stable activity and high selectivity for the formation of light olefin [24-27]. A positive effect of other transition metals such as La, Mo, Ta, V, and $\mathrm{Zr}$ for FTS and WGS activation has also been reported [3,27-33]. Nanoparticles may offer different morphology and increase surface area that, in theory, should enhance the reaction rates as a result of more available catalyst sites. Therefore, for exothermic reactions such as CO hydrogenations, nanocatalysts are supposed to be more effective and selective. Although numerous studies on Fe-based FTS catalysts have been reported, the investigations on the effect of lanthanum and barium on the catalysts are limited, and no literature about the effect of combination of lanthanum and barium on the catalysts is reported as well.

In this study, the microemulsion method has been applied to prepare four different Fe catalysts in order to investigate the effects of lanthanum, barium, and their mixture on catalyst morphology, activity, and product selectivity in FischerTropsch synthesis. The catalysts were tested in a fixed-bed stainless steel reactor under FTS conditions.

\section{Experimental}

\subsection{Catalyst preparation}


Nanostructure iron catalysts were prepared through water-in-oil microemulsion method by adding water solution of a metal precursor, $\mathrm{FeCl}_{3} \cdot 6 \mathrm{H}_{2} \mathrm{O}$ (Merck, > 99\%), to a mixture of an oil phase containing 1-butanol (Aldrich, $>$ 99\%) and chloroform (Aldrich, $>99 \%$ ) with a ratio of $1: 1$, and sodium dodecyl sulfate (SDS) as a surfactant. Hydrazine $(25 \%-30 \%)$ was added as precipitating agent and the solution was stirred for $4 \mathrm{~h}$. The resulting mixture was left aside to decant overnight. The solid was recovered by centrifugation and washed thoroughly with distilled water, ethanol, and acetone. Finally, the samples were dried overnight at $110{ }^{\circ} \mathrm{C}$ and subsequently calcined in air at $400{ }^{\circ} \mathrm{C}$ for $4 \mathrm{~h}$. Nanostructured copper oxide, lanthanum oxide, and barium oxide were prepared similarly. In the subsequent step, the two preparations were mixed together. The promoted catalysts were dried at $110{ }^{\circ} \mathrm{C}$ for $15 \mathrm{~h}$ and calcined at $400{ }^{\circ} \mathrm{C}$ for $4 \mathrm{~h}$ in air. Figure 1 shows the catalyst preparation flow diagram. The catalyst compositions were designated in terms of the atomic ratios as $100 \mathrm{Fe} / 4 \mathrm{Cu}$, $100 \mathrm{Fe} / 4 \mathrm{Cu} / 2 \mathrm{La}, 100 \mathrm{Fe} / 4 \mathrm{Cu} / 1 \mathrm{La} / 1 \mathrm{Ba}, 100 \mathrm{Fe} / 4 \mathrm{Cu} / 2 \mathrm{Ba}$. All samples were pressed into pellets, crushed, and sieved to obtain particle sizes in the range of 30-40 mesh.

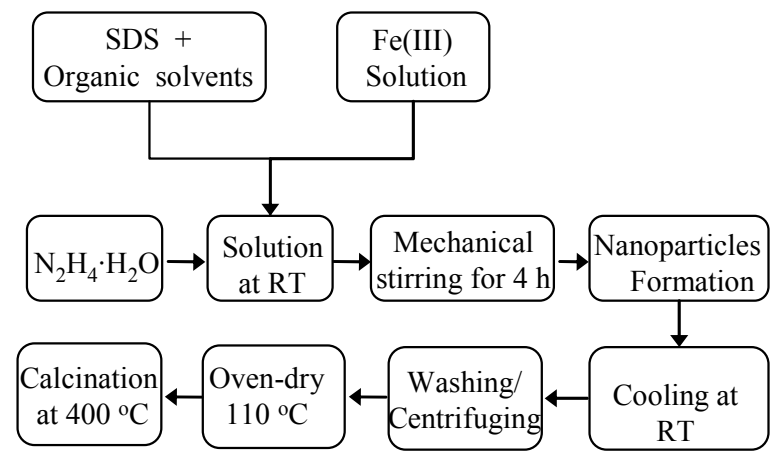

Fig. 1. Catalyst preparation flow diagram.

\subsection{Catalyst characterization}

BET surface area and pore volume were determined by $\mathrm{N}_{2}$ physisorption using a Micromeritics ASAP 2010 automated system. A $0.5 \mathrm{~g}$ catalyst sample was degassed in the system at $100{ }^{\circ} \mathrm{C}$ for $1 \mathrm{~h}$ and then at $300{ }^{\circ} \mathrm{C}$ for $2 \mathrm{~h}$ prior to analysis. Average particle size of the calcined powders was measured by LEO 912AB TEM. The XRD patterns of fresh catalysts were conducted with a Philips PW1840 X-ray diffractometer with monochromatized $\mathrm{Cu}\left(K_{a}\right)$ radiation. Temperature-programmed reduction (TPR) profiles of the calcined catalysts were recorded using a Micromeritics TPD-TPR 290 system. The TPR of $50 \mathrm{mg}$ of each sample was performed in $5 \% \mathrm{H}_{2}-95 \%$ Ar gas mixture. The samples were heated from 50 to $900{ }^{\circ} \mathrm{C}$ at $10{ }^{\circ} \mathrm{C} / \mathrm{min}$.

The surface basicity was measured by tempera- ture-programmed desorption of carbon dioxide $\left(\mathrm{CO}_{2}\right.$ chemisorbed at $100{ }^{\circ} \mathrm{C}$ ) on the reduced and purged catalyst $(0.5 \mathrm{~g})$ packed in a shallow-bed quartz reactor with a low dead volume from 80 to $430{ }^{\circ} \mathrm{C}$ at $5{ }^{\circ} \mathrm{C} / \mathrm{min}$. Helium was used as a carrier gas. A thermal conductivity detector was used to measure the $\mathrm{CO}_{2}$ desorbed in the TPD quantitatively. The composition of catalyst was determined by atomic absorption instrument (Perkin-Elmer model 2380).

\subsection{Reactor system and operation procedure}

As shown in Fig. 2, the catalytic reaction experiments were conducted in a fixed-bed stainless steel reactor. Flow rate of inlet gases and reactor pressure were controlled by electronic mass flow and pressure controllers, respectively. A four heating zone furnace with temperature controller and indicator supplied the required reaction heat. The catalyst $(1.1 \mathrm{~g})$ was loaded in the reactor and reduced by a $10 \%$ $\mathrm{H}_{2}-90 \% \mathrm{~N}_{2}$ flow gas for $3 \mathrm{~h}$. The catalyst activation was followed in a stream of synthesis gas with $\mathrm{H}_{2} / \mathrm{CO}=1$ and space velocity of $1.5 \mathrm{nl} /(\mathrm{h} \cdot \mathrm{g})$ for $24 \mathrm{~h}$ at $270{ }^{\circ} \mathrm{C}$ in atmospheric pressure. After the activation process, the reactor pressure and temperature raised to 18 bar and $290{ }^{\circ} \mathrm{C}$, respectively. The reaction was initiated in synthesis gas stream with $\mathrm{H}_{2} / \mathrm{CO}=1.1$ and GHSV of $3 \mathrm{nl} /(\mathrm{h} \cdot \mathrm{g})$.

The products were analyzed by a gas chromatography (Varian CP 3800) equipped with three subsequent connected columns. Two packed columns connected to two thermal conductivity detectors (TCD), which used for analyzing $\mathrm{H}_{2}$, $\mathrm{CO}, \mathrm{CO}_{2}, \mathrm{CH}_{4}$, and other non-condensable gases. A Petrocol Tm DH100 fused silica capillary column was attached to a flame ionization detector (FID) for analyzing organic liquid products [34,35]. The activities and product selectivities were assessed after $72 \mathrm{~h}$ from initial time.

\section{Results and discussion}

Alkaline metals are usually used as promoters since they can modify the adsorption pattern of the reactants $\left(\mathrm{H}_{2}\right.$ and $\mathrm{CO}$ ) on the active sites. Taking K-promoted Fe based catalyst for example, chemisorption of $\mathrm{CO}$ over the catalyst is enhanced since iron intends to withdraw electronic density from potassium, and consequently, strengthen the $\mathrm{Fe}-\mathrm{CO}$ bond [36]. At higher amount of alkali metals, CO dissociation proceeds faster than carbon hydrogenation. Therefore, it produces an excessive amount of carbon deposition and consequently deactivates the catalyst surface [37]. In this paper, using $\mathrm{La}$ and $\mathrm{Ba}$ as promoters, four catalysts were prepared including $100 \mathrm{Fe} / 4 \mathrm{Cu}, 100 \mathrm{Fe} / 4 \mathrm{Cu} / 2 \mathrm{La}$, $100 \mathrm{Fe} / 4 \mathrm{Cu} / 1 \mathrm{La} / 1 \mathrm{Ba}$, and $100 \mathrm{Fe} / 4 \mathrm{Cu} / 2 \mathrm{Ba}$, and confirmed by elemental analysis. 


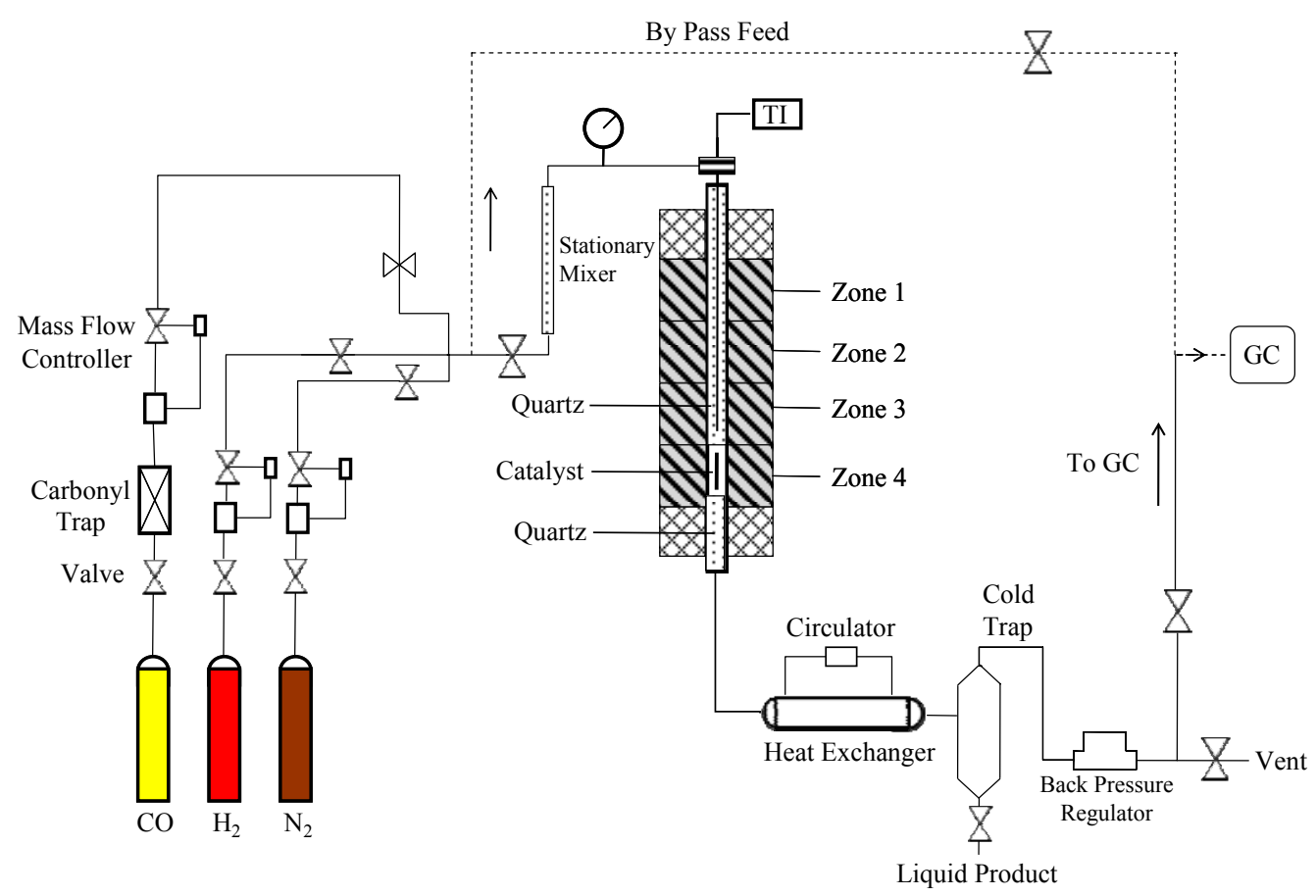

Fig. 2. Catalyst test system.

Table 1 shows the results of the BET surface areas, pore volumes, and pore sizes of the catalysts. By adding lanthanum, barium, and their combination particles to the conventional catalyst, the BET surface area and pore volume decreased. Furthermore, it might promote the aggregation of the catalyst crystallites and block up the pores. Therefore, the prepared catalysts did not have high surface area, which was different with silica [34].

Table 1 BET surface area, pore volume, and pore size of the catalysts

\begin{tabular}{lcccc}
\hline Catalyst & $\begin{array}{c}\text { BET surface } \\
\text { area }\left(\mathrm{m}^{2} / \mathrm{g}\right)\end{array}$ & $\begin{array}{c}\text { Pore volume } \\
\left(\mathrm{cm}^{3} / \mathrm{g}\right)\end{array}$ & \multicolumn{2}{c}{ Particle size $(\mathrm{nm})$} \\
\hline $100 \mathrm{Fe} / 4 \mathrm{Cu}$ & 48.2 & 0.25 & 24.5 & 25.1 \\
$100 \mathrm{Fe} / 4 \mathrm{Cu} / 2 \mathrm{La}$ & 44.1 & 0.22 & 26.6 & 26.9 \\
$100 \mathrm{Fe} / 4 \mathrm{Cu} / 1 \mathrm{La} / 1 \mathrm{Ba}$ & 46.4 & 0.23 & 25.3 & 26.3 \\
$100 \mathrm{Fe} / 4 \mathrm{Cu} / 2 \mathrm{Ba}$ & 45.2 & 0.21 & 28.1 & 28.3 \\
\hline
\end{tabular}

The catalysts were characterized by XRD after calcinations. Figure 3 shows the XRD patterns of the prepared catalysts. As shown in this figure, no new phase was detected when La and Ba were added. All the catalysts showed cubic hematite crystal structure according to the JCPDS database. The characteristic peak at $2 \theta=33.3^{\circ}$ corresponding to the hematite (104) plane was used to calculate the average metal particle size by the Scherrer equation [38].

The particle sizes of the samples determined by XRD are summarized in Table 1. In general, particle sizes estimated from different techniques can provide different physical meanings. The XRD particle size $\left(d_{\mathrm{XRD}}\right)$ obtained from

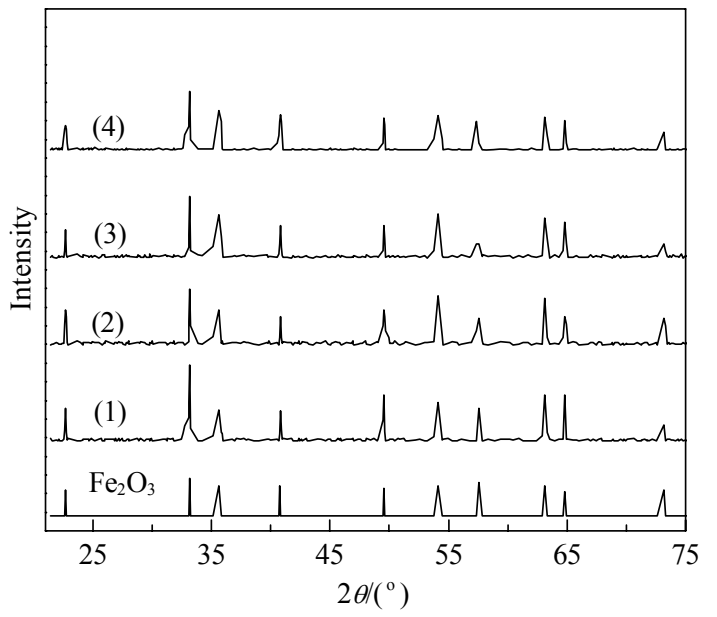

Fig. 3. XRD patterns of the fresh catalysts. (1) $100 \mathrm{Fe} / 4 \mathrm{Cu}$; (2) $100 \mathrm{Fe} / 4 \mathrm{Cu} / 2 \mathrm{La}$; (3) $100 \mathrm{Fe} / 4 \mathrm{Cu} / 1 \mathrm{La} / 1 \mathrm{Ba}$; (4) $100 \mathrm{Fe} / 4 \mathrm{Cu} / 2 \mathrm{Ba}$.

XRD pattern indicates the average particle size. In addition, the average particle size can also be obtained by the Scherrer equation, $d=k \lambda / \beta(\theta) \operatorname{Cos} \theta$, from the peak width in a wide angle X-ray scattering (WAXS) measurement of the material, where $\lambda$ is the X-ray wavelength $(\mathrm{nm}), \beta(\theta)$ is the full width at half maximum (rad) of the identified peak, $\theta$ is the diffraction angle, and $k$ is the typical constant of the equipment.

The TEM images of the catalysts are illustrated in Fig. 4. Although TEM revealed that the nanoparticle size was in the range of 10-30 nm, no distinguished difference was 


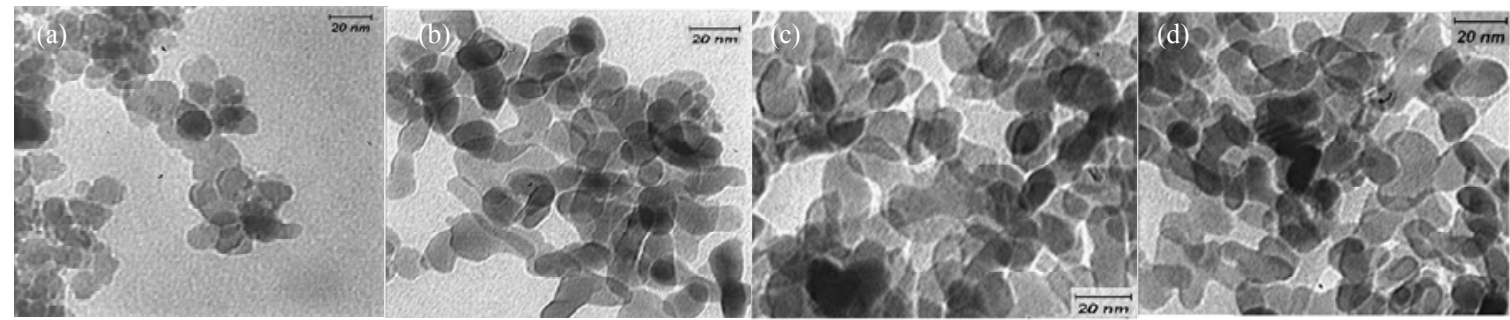

Fig. 4. TEM images of the catalysts. (a) $100 \mathrm{Fe} / 4 \mathrm{Cu}$; (b) $100 \mathrm{Fe} / 4 \mathrm{Cu} / 2 \mathrm{La}$; (c) $100 \mathrm{Fe} / 4 \mathrm{Cu} / 1 \mathrm{La} / 1 \mathrm{Ba}$; (d) $100 \mathrm{Fe} / 4 \mathrm{Cu} / 2 \mathrm{Ba}$.

observed.

Carbon dioxide uptakes are often used as a probe to determine the intensity and strength of the surface basicity sites in solid materials [39]. Table 2 shows the quantitative results on $\mathrm{CO}_{2}$-TPD. As represented $\mathrm{CO}_{2}$-TPD curves in Fig. 5, there are several peaks. A small peak at about $120^{\circ} \mathrm{C}$ and a long tail at a temperature above $250{ }^{\circ} \mathrm{C}$ are traced in all profiles. The small peak at low temperature corresponds to weak $\mathrm{CO}_{2}$ physical adsorption. The peak tail above 250 ${ }^{\circ} \mathrm{C}$ is attributed to the slow decomposition of metal carbonates formed during $\mathrm{CO}_{2}$ adsorption [40]. In the temperature range $100-400{ }^{\circ} \mathrm{C}$, two distinct peaks are attributed to the desorption of $\mathrm{CO}_{2}$ which interacted moderately with the surface basic sites. The $\mathrm{CO}_{2}$-TPD results indicate that the amount of carbon dioxide desorption in the promoted catalysts was more than the non-promoted catalyst. The desorption temperature of $\mathrm{CO}_{2}$ over Ba-promoted catalysts increased and the peak tail above $280{ }^{\circ} \mathrm{C}$ was broader. The $\mathrm{CO}_{2}$-TPD results (in Fig. 5) show that the catalyst basicity

Table $2 \mathrm{CO}_{2}$-TPD of quantitative results

\begin{tabular}{lc}
\hline Catalyst & $\mathrm{CO}_{2}$ desorption $\left(\mathrm{mmol} / \mathrm{g}_{\text {cat }}\right)$ \\
\hline $100 \mathrm{Fe} / 4 \mathrm{Cu}$ & 123 \\
$100 \mathrm{Fe} / 4 \mathrm{Cu} / 2 \mathrm{La}$ & 575 \\
$100 \mathrm{Fe} / 4 \mathrm{Cu} / 1 \mathrm{La} / 1 \mathrm{Ba}$ & 747 \\
$100 \mathrm{Fe} / 4 \mathrm{Cu} / 2 \mathrm{Ba}$ & 1062 \\
\hline
\end{tabular}

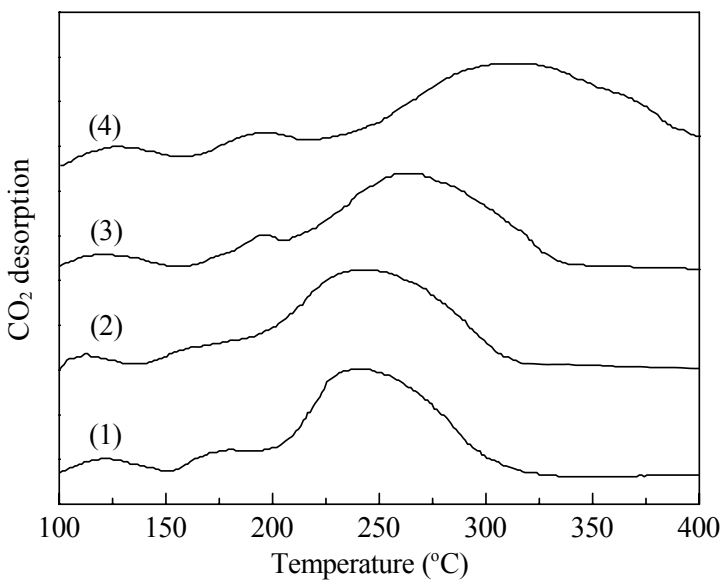

Fig. 5. $\mathrm{CO}_{2}-\mathrm{TPD}$ profiles of the catalysts. (1) $100 \mathrm{Fe} / 4 \mathrm{Cu}$; (2) $100 \mathrm{Fe} / 4 \mathrm{Cu} / 2 \mathrm{La}$; (3) $100 \mathrm{Fe} / 4 \mathrm{Cu} / 1 \mathrm{La} / 1 \mathrm{Ba}$; (4) $100 \mathrm{Fe} / 4 \mathrm{Cu} / 2 \mathrm{Ba}$. increases in the order $100 \mathrm{Fe} / 4 \mathrm{Cu}<100 \mathrm{Fe} / 4 \mathrm{Cu} / 2 \mathrm{La}<$ $100 \mathrm{Fe} / 4 \mathrm{Cu} / 1 \mathrm{La} / 1 \mathrm{Ba}<100 \mathrm{Fe} / 4 \mathrm{Cu} / 2 \mathrm{Ba}$, which is consistent with the oxides structure and their contents [37].

Figure 6 shows the $\mathrm{H}_{2}$-TPR profiles of the catalysts. $\mathrm{H}_{2}$-TPR determines the reduction behavior of the catalysts. The first stage is ascribed to the transformations of $\mathrm{CuO}$ to $\mathrm{Cu}$. The second stage is attributed to the transformation of $\mathrm{Fe}_{2} \mathrm{O}_{3}$ to $\mathrm{Fe}_{3} \mathrm{O}_{4}$, and the third stage represents the transformation of $\mathrm{Fe}_{3} \mathrm{O}_{4}$ to $\mathrm{Fe}$. It is well known that $\mathrm{CuO}$ can be easily reduced at lower temperature in $\mathrm{H}_{2}$ atmosphere $[41,42]$. Table 3 shows the quantitative results of $\mathrm{H}_{2}$ consumption for fresh catalysts in $\mathrm{H}_{2}$-TPR.

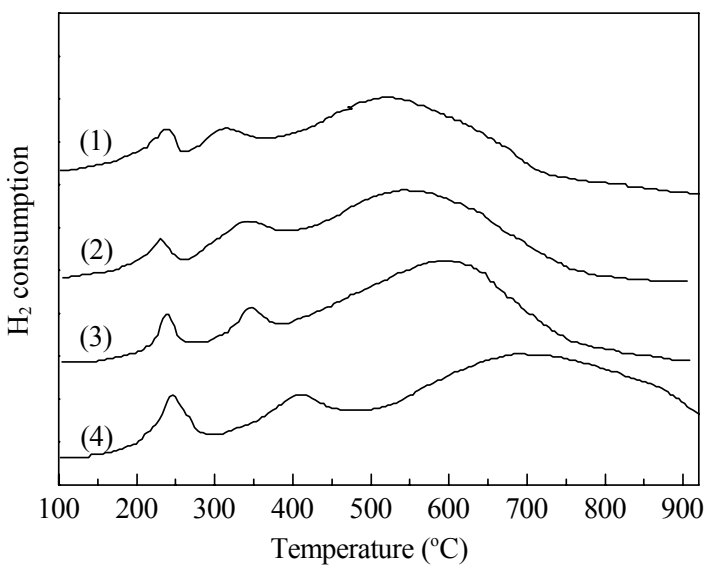

Fig. 6. $\mathrm{H}_{2}-\mathrm{TPR}$ profiles of the catalysts. (1) $100 \mathrm{Fe} / 4 \mathrm{Cu}$; (2) $100 \mathrm{Fe} / 4 \mathrm{Cu} / 2 \mathrm{La}$; (3) $100 \mathrm{Fe} / 4 \mathrm{Cu} / 1 \mathrm{La} / 1 \mathrm{Ba}$; (4) $100 \mathrm{Fe} / 4 \mathrm{Cu} / 2 \mathrm{Ba}$.

Contrary to the catalysts basicity, $\mathrm{H}_{2}$ concentration on the surface decreases in the order $100 \mathrm{Fe} / 4 \mathrm{Cu} / 2 \mathrm{Ba}$ $>100 \mathrm{Fe} / 4 \mathrm{Cu} / 1 \mathrm{La} / 1 \mathrm{Ba}>100 \mathrm{Fe} / 4 \mathrm{Cu} / 2 \mathrm{La}>100 \mathrm{Fe} / 4 \mathrm{Cu}$. With the catalyst basicity increasing, the $\mathrm{H}_{2}$ adsorption on the surface was considerably suppressed. Therefore, the catalyst reducibility declined at higher temperatures [43]. Promoters result in enhancement of the reduction temperature, catalyst activity, and reaction time. Copper accelerates the deactivation of the catalyst [44], whereas adding both barium and lanthanum as promoters, apparently, improves the FTS activity of iron-based catalysts. Thus, promoted iron catalysts have higher FTS and WGS activity than non-promoted catalysts. 
Table 3 Quantitative results of $\mathrm{H}_{2}$ consumption for fresh catalysts in $\mathrm{H}_{2}$-TPR

\begin{tabular}{lccc}
\hline \multirow{2}{*}{ Catalyst } & Peak $\left({ }^{\circ} \mathrm{C}\right)$ & \multicolumn{2}{c}{$\mathrm{H}_{2}$ consumption } \\
\cline { 3 - 4 } $100 \mathrm{Fe} / 4 \mathrm{Cu}$ & 282 & 0.27 & \\
& 323 & & 0.34 \\
& 522 & & 0.47 \\
$100 \mathrm{Fe} / 4 \mathrm{Cu} / 2 \mathrm{La}$ & 292 & 0.31 & \\
& 383 & & 0.39 \\
& 565 & & 0.49 \\
$100 \mathrm{Fe} / 4 \mathrm{Cu} / 1 \mathrm{La} / 1 \mathrm{Ba}$ & 300 & 0.32 & \\
& 400 & & 0.41 \\
& 620 & & 0.54 \\
$100 \mathrm{Fe} / 4 \mathrm{Cu} / 2 \mathrm{Ba}$ & 295 & 0.29 & \\
& 412 & & 0.41 \\
& 680 & & 0.43 \\
\hline
\end{tabular}

${ }^{\mathrm{a}} \mathrm{M}=\mathrm{Fe}+\mathrm{Cu}$.

$\mathrm{H}_{2} \mathrm{O}$ plays an important role in changing the iron phase composition during FTS process. Reversible WGS reaction accompanied with FTS on iron-based catalyst has been recognized well (Eqs. (1) and (2)) [45].

$$
\begin{gathered}
r_{\mathrm{WGS}}=r_{\mathrm{CO} 2} \\
r_{\mathrm{FTS}}=r_{\mathrm{CO}}-r_{\mathrm{WGS}}
\end{gathered}
$$

As the WGS reaction consumes the water produced by FTS, an inequality is always observed:

$$
r_{\mathrm{WGS}} \leq r_{\mathrm{FTS}}
$$

Figure 7 shows FTS and WGS rates. During FTS process, part of produced water from FTS reaction was consumed by WGS reaction.

$\mathrm{Fe}_{3} \mathrm{O}_{4}$ is the active site for WGS reaction on iron-based catalyst [46], while lanthanum or barium is only an electronic donor. The incorporation of lanthanum and/or barium into iron-based catalysts can promote $\mathrm{CO}$ adsorption and concentrate $\mathrm{CO}$ species, which results in WGS reaction shifting to right to improve the WGS activity. The high WGS activity decreases the $\mathrm{H}_{2} \mathrm{O}$ pressure and stabilizes the iron carbides [47]. The double promotions of $\mathrm{Ba}$ and $\mathrm{La}$ significantly improved the FTS and WGS activities, which are due to the synergistic effect and basicity of promoters.

Product selectivities are indicated in Table 4. It shows the selectivity for gaseous, light hydrocarbons (methane and $\left.\mathrm{C}_{2}-\mathrm{C}_{4}\right)$, and heavy hydrocarbons $\left(\mathrm{C}_{5^{+}}\right)$. All of these results

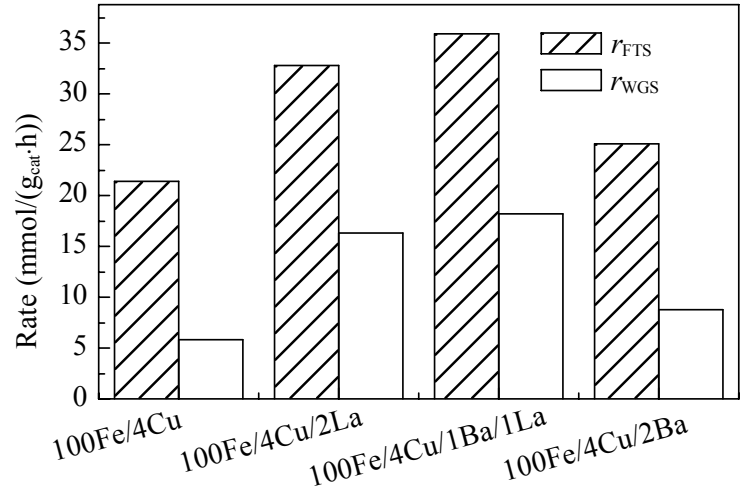

Fig. 7. FTS and WGS rates of the catalysts.

imply that the chain growth reaction is facilitated and the hydrogenation reaction is restrained while the promoter was added into the catalysts. Both the amount of the promoters and the reaction conditions influenced the product selectivity. The mole fraction of hydrocarbons was obtained by the Anderson-Schulz-Flory (ASF) equation [2] as a function of the carbon number $i$ and the chain growth probability $\alpha$ (Eq. (4)):

$$
x_{i}=(1-\alpha) \alpha^{i-1}
$$

Figure 8 shows the promoters effect on $\mathrm{CO}$ conversion versus time on stream. The results show that the promoters facilitate the $\mathrm{CO}$ dissociative adsorption, leading to a higher coverage of carbon species on the surface and thus conduct to the chain growth reaction.

\begin{tabular}{|c|c|c|c|c|c|c|c|c|}
\hline \multirow{2}{*}{ Catalyst } & \multirow{2}{*}{$\begin{array}{c}\text { CO conversion } \\
(\%) \\
\end{array}$} & \multicolumn{6}{|c|}{ Selectivity $(\mathrm{mol} \%)$} & \multirow{2}{*}{$\alpha$} \\
\hline & & $\mathrm{CH}_{4}$ & $\mathrm{C}_{2}-\mathrm{C}_{4}$ & $\mathrm{C}_{5}-\mathrm{C}_{12}$ & $\mathrm{C}_{13}-\mathrm{C}_{19}$ & $\mathrm{C}_{19+}$ & $\mathrm{CO}_{2}{ }^{\mathrm{a}}$ & \\
\hline $100 \mathrm{Fe} / 4 \mathrm{Cu}$ & 59.6 & 15.96 & 32.92 & 15.79 & 10.35 & 7.69 & 17.29 & 0.61 \\
\hline $100 \mathrm{Fe} / 4 \mathrm{Cu} / 2 \mathrm{Ba}$ & 68.5 & 10.44 & 24.15 & 26.46 & 11.39 & 7.25 & 20.31 & 0.71 \\
\hline $100 \mathrm{Fe} / 4 \mathrm{Cu} / 2 \mathrm{La}$ & 71.8 & 12.32 & 26.19 & 20.91 & 10.64 & 6.51 & 23.43 & 0.66 \\
\hline $100 \mathrm{Fe} / 4 \mathrm{Cu} / 1 \mathrm{Ba} / 1 \mathrm{La}$ & 79.6 & 10.81 & 25.30 & 21.80 & 10.50 & 6.56 & 25.03 & 0.68 \\
\hline
\end{tabular}

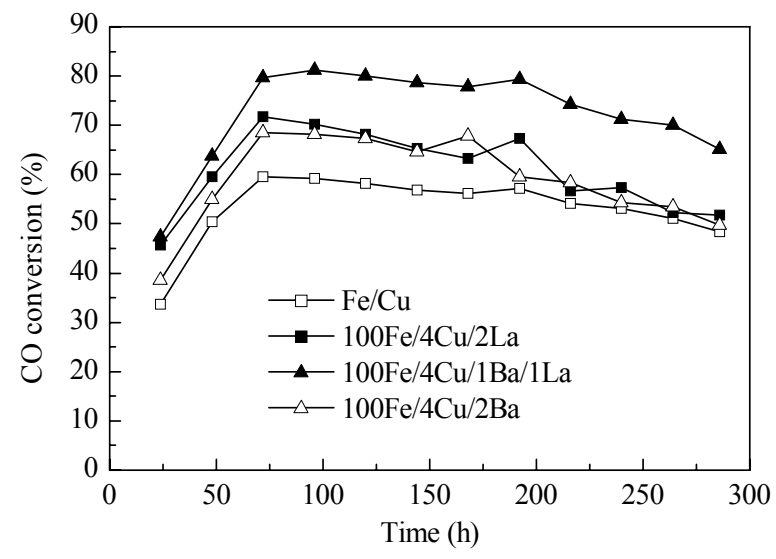

Fig. 8. Promoter effect on CO conversion versus time on stream.

Table 4 The activity and selectivity of the catalysts

Reaction conditions: time on stream $72 \mathrm{~h}, 290^{\circ} \mathrm{C}, 1.8 \mathrm{MPa}, \mathrm{H}_{2} / \mathrm{CO}=1.1, \mathrm{SV}=3 \mathrm{nl} /(\mathrm{g} \cdot \mathrm{h})$.

${ }^{*}$ Selectivity for oxygenates was negligible $(<2.5 \%)$ in all cases. 


\section{Conclusions}

Nanostructured iron catalysts were successfully prepared by the microemulsion method. The effect of lanthanum and barium was investigated on the phase structure of nanosized iron catalysts and the performance of $\mathrm{CO}$ hydrogenation. By adding $\mathrm{Ba}$ and $\mathrm{La}$ promoters into nanosized iron catalysts, it was found that there was significantly influence on the catalytic activity during the Fischer-Tropsch synthesis. The improvement of the catalytic performances can be attributed to the effect of the promoters on $\mathrm{H}_{2}$ and $\mathrm{CO}$ adsorption, which further significantly affects the FTS performances of the catalysts. As compared with individual promoter of $\mathrm{Ba}$ or $\mathrm{La}$, double promoters of $\mathrm{Ba}$ and La significantly improve the FTS and WGS activities, which are due to the synergistic effect and the basicity of promoters.

\section{Acknowledgements}

We are grateful to the Research and Development of National Iranian Oil Company (NIOC) for financial support, which enabled this work to be undertaken. We also express our thanks to Central Laboratory of Ferdowsi University of Mashhad for recording TEM micrographs.

\section{References}

1 Davis B H. Catal Today, 2009, 141: 25

2 Van Der Laan G P, Beenackers A A C M. Catal Rev-Sci Eng, 1999, 41: 255

3 Zhao L L, Liu G R, Li J L. Chin J Catal, 2009, 30: 637

4 Pour A N, Zamani Y, Tavasoli A, Kamali Shahri S M, Taheri S A. Fuel, 2008, 87: 2004

5 Jing G H, Li J H, Hao J M. Chin J Catal, 2009, 30: 973

6 Pour A N, Kamali Shahri S M, Zamani Y, Irani M, Tehrani S. J Nat Gas Chem, 2008, 17: 242

7 Pouretedal H R, Kadkhodaie A. Chin J Catal, 2010, 31: 1328

8 Li J W, Zhan Y Y, Zhang F L, Lin X Y, Zheng Q. Chin J Catal, 2008, 29: 346

9 Teng B T, Chang J, Wan H J, Liu J Q, Zheng S C, Liu Y, Liu Y, Guo X H. Chin J Catal, 2007, 28: 687

10 Dry M E. Catal Sci Technol, 1981, 1: 159

11 Ding M, Yang Y, Wu B, Wang T, Xiang H, Li Y. Fuel Process Technol, 2011, 92: 2353

12 Kang S H, Bae J W, Cheon J Y, Lee Y J, Ha K S, Jun K W, Lee D H, Kim B W. Appl Catal B, 2011, 103: 169

13 Ojeda M, Nabar R, Nilekar A U, Ishikawa A, Mavrikakis M, Iglesia E. J Catal, 2010, 272: 287

14 Pour A N, Housaindokht M R, Zarkesh J, Irani M, Ganji E B. $J$ Ind Eng Chem, 2012, 18: 597

15 Luo M, O’Brien R J, Bao S, Davis B H. Appl Catal A, 2003, 239: 111

16 Bukur D B, Mukesh D, Patel S A. Ind Eng Chem Res, 1990,
29: 194

17 Pour A N, Kamali Shahri S M, Zamani Y, Zamaniyan A. J Nat Gas Chem, 2010, 19: 193

18 Özkara-Aydınoğlu Ş, Ataç Ö, Gül Ö F, Kınayyiğit Ş, Şal S, Baranak M, Boz İ. Chem Eng J, 2012, 181-182: 581

19 Suo H, Wang S, Zhang C, Xu J, Wu B, Yang Y, Xiang H, Li Y W. J Catal, 2012, 286: 111

20 Pendyala V R R, Jacobs G, Mohandas J C, Luo M, Ma W, Gnanamani M K, Davis B H. Appl Catal A, 2010, 389: 131

21 Xiang B, Xu H Y, Li W Z. Chin J Catal, 2007, 28: 841

22 Li S, Li A, Krishnamoorthy S, Iglesia E. Catal Lett, 2001, 77: 197

23 Wang C, Wang Q X, Sun X D, Xu L Y. Catal Lett, 2005, 105: 93

24 Bai L, Xiang H W, Li Y W, Han Y Z, Zhong B. Fuel, 2002, 81: 1577

25 Malessa R, Baerns M. Ind Eng Chem Res, 1988, 27: 279

26 Lohitharn N, Goodwin J G, Lotero E. J Catal, 2008, 255: 104

27 Shi H B, Shen S K. Chin J Catal, 2006, 27: 1096

28 Zhou X F, Chen Q L, Tao Y W, Weng H X. Chin J Catal, 2011, 32: 1156

29 Dai X, Yu C C, Li R J, Shi H B, Shen S K. Chin J Catal, 2006, 27: 904

30 Dai X P, Yu C C, Li R J. Chin J Catal, 2007, 28: 1047

31 Ma X M, Lin G D, Zhang H B. Chin J Catal, 2006, 27: 1019

32 Yang Y, Wang Y D, Liu S, Song Q Y, Xie Z K, Gao Z. Chin J Catal, 2007, 28: 1028

33 Feyzi M, Irandoust M, Mirzaei A A. Fuel Process Technol, 2011, 92: 1136

34 Zamani Y, Yousefian S H, Nakhaei Pour A, Moshtari B, Bahadoran F, Taheri S A. Chem Eng Trans, 2010, 21: 1045

35 Pour A N, Kamali Shahri S M, Bozorgzadeh H R, Zamani Y, Tavasoli A, Ahmadi M M. Appl Catal A, 2008, 348: 201

36 Zhang C H, Yang Y, Teng B T, Li T Z, Zheng H Y, Xiang H W, Li Y W. J Catal, 2006, 237: 405

37 Herranz T, Rojas S, Pé rez-Alonso F J, Ojeda M, Terreros P, Fierro J L G. Appl Catal A, 2006, 311: 66

38 Scherrer P, Gottingen N G W. Math-Pys Kl, 1918, 2: 96

39 Bouarab R, Cherifi O, Auroux A. Thermochim Acta, 2005, 434: 69

40 Yang J, Sun Y, Tang Y, Liu Y, Wang H, Tian L, Wang H, Zhang Z, Xiang H, Li Y. J Mol Catal A, 2006, 245: 26

41 Qing M, Yang Y, Wu B S, Xu J, Zhang C H, Gao P, Li Y W. J Catal, 2011, 279: 111

42 Li S, Krisyhnamoorthy S, Li A, Meitzner G D, Iglesia E. $J$ Catal, 2002, 206: 202

43 Wu B, Tian L, Bai L, Zhang Z, Xiang H, Li Y W. Catal Commun, 2004, 5: 253

44 Dry M E, Oosthuizen G J. J Catal, 1968, 11: 18

45 Bukur D B, Nowicki L, Manne R K, Lang X S. J Catal, 1995 , 155: 366

46 Li S, O’Brien R J, Meitzner G D, Hamdeh H, Davis B H, Iglesia E. Appl Catal A, 2001, 219: 215

47 Yang Y, Xiang H W, Xu Y Y, Bai L, Li Y W. Appl Catal A, 2004, 266: 181 